\title{
Photography: My New Score
}

\author{
Mary G. O Brien
}

Department of Music, Sunday's Well., UCC

\section{Introduction}

The aim of this research is to demonstrate how photography is used as a creative tool in my compositional process. Purpose-built pictures are created solely with the goal of acting as musical scores, called graphic scores, from which performers improvise. This paves a way for me, the composer, to communicate my compositional ideas to the performers, resulting in new soundscapes and original artworks, without the restrictive barriers placed upon me, the composer, by convention.

As an artist, the objective is to capture unique moments in time, where images are taken naturally or by manipulating the camera in a variety of predetermined ways. This idea could work with any picture, but for me, it is the innate musical language that I have developed over the years of my conventional musical training, that leads me to the precise construction of these new compositions.

\section{Inspiration}

Initially, I was inspired by the writings of John Cage in his book Silence (1961), which helped to open my mind to the world around me. At the beginning of this research, I performed 4'33" (John Cage) in various locations as I searched for musical inspiration and potential silence. I took photographs of these places as a record of this work.

\section{"From nothing to something"}

Later, as I visited art galleries around Europe, I discovered the black and white artworks of artists such as Robert Rauschenberg: the artist who inspired John Cage "to do for music, what he had already done for art". This led to my notion of working with "Nothing" the blank canvas, which became "Something" - a photograph, for example, thus triggering inspiration for creating new musical compositions.

\section{Photography: My new process}

Take this simple picture (fig.1) as an example: - 

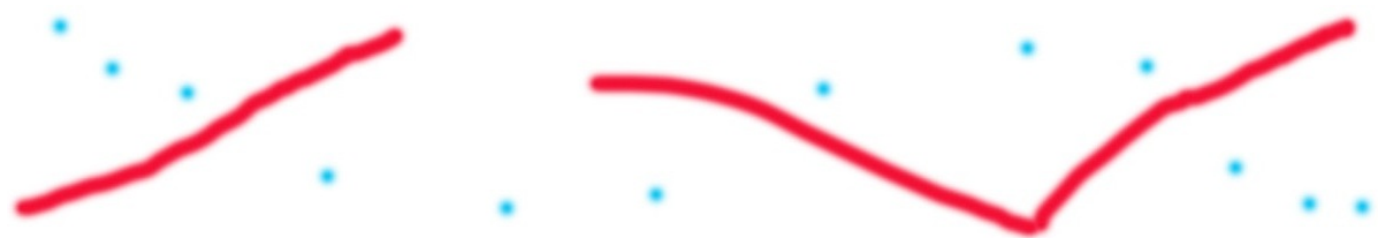

Figure 1: Dots and Lines Graphic Score - Source: Author

From this, I do not know the exact pitches the performers will play, but I know that I will hear a series of short notes from the performer of the blue dots, and a series of long notes from the player of the red lines. If I ask the performers to read from left to right, I have even more control. I could give precise performance instructions on some occasions, or alternatively, I could just hand the performers the picture to improvise on and we would discuss the implications of the performance thereafter. Both methods produce interesting results.

Therefore, as I design each picture, I have power over the density of the sound, known as 'texture' in the musical world. The picture can also be used to create a certain sense of mood using colour, and so on.

I discovered that displaying these photographs as part of my public performances of these pieces, gave a sense of space and meaning to the audience. This idea was inspired by CrossArt Ensemble: a group from Germany, who provided a concert and workshop to University College Cork music students in February 2013.

\section{Rocky Bay string quartet}

Capturing footage after a big winter storm in January 2014 provided a video of the waves hitting off the rocks, in Rocky Bay, Co Cork. I focused the camera on one rock for the duration of the video, with the help of my tripod. This created a still, but moving image, as the waves tossed and twirled around the space (fig. 2). As I recorded this footage, over a long period of time, I observed the natural soundscape of the area. This inspired me to compose a new piece for the Vanbrugh String Quartet, incorporating ideas devised from this picture. The stillness of the rocks, the violent movement of the water, and even a seagull jumping up and down to avoid the waves on a nearby rock, created the musical material needed to develop this piece.

To facilitate ease of reading, I recorded my thoughts on standard notation for these players. However, on this occasion, I also requested the musicians to improvise following coloured lines in the final section, as their sound represented the intensity of the storm. This piece was played at a University College Cork Workshop, with the video played at double and then quadruple speed behind them. The players were encouraged to watch this video as they sight-read the piece, creating interesting results. 


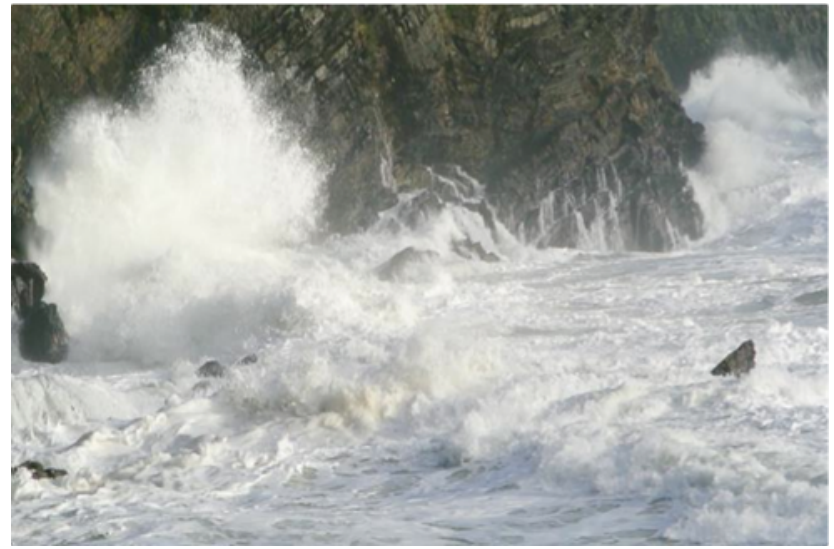

Figure 2: Rocky Bay during a winter storm — Source: Author

\section{Camera manipulation}

Later, I decided that I should try to create some more unusual pictures, which I developed by manipulating the lighting and the shutter speed of the camera. These were designed with the intention of re-orchestrating my sound world to create a more ethereal quality, which could not have been achieved previously. Shaking the camera and capturing reflections, led to a series of photographs that would have been unimaginable at the initiation of this section of my thesis called Darkness: Illuminations.

\section{Edinburgh lights: quiet music ensemble}

Taking a trip to Edinburgh to capture the sounds of the zoo led to an interesting experience. Each night, I sat in the front seat on the second floor of a double decker bus on my return journey back to my hotel. Rather than wasting these precious moments, I set my camera to a long exposure mode. Using a slow shutter speed, I shook the camera resulting in unconventional shots. These pictures in turn became a slide show, which the members of the Quiet Music Ensemble (of which my supervisor Mr. John Godfrey is a part of) improvised on as part of another University College Cork student workshop. Each player was given a colour to follow on the screen. The results were ethereal in quality. This newly constructed score portrayed my intentions in an unprecedented way (fig. 3).

\section{Edinburgh illuminations}

"Edinburgh Illuminations" is a merging of photographs taken at a park of solar lights in Edinburgh City Centre during the same trip. I shook the camera in various ways and on some occasions pretended to trace letters in the air, whilst the camera was set at a slow shutter speed to produce the effects as can be seen in fig. 4 below. I extracted parts of each of these photographs and layered them together in Adobe Photoshop. At a recent concert called "It's Not Just Black and White, Girl...", part of Culture Night 2015, I asked 


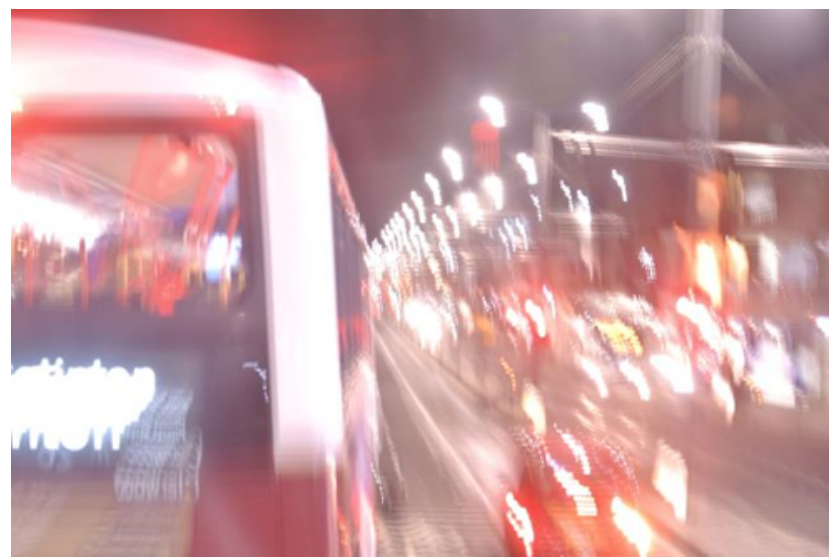

Figure 3: Edinburgh Lights: Camera Manipulation whilst sitting on a moving doubledecker bus - Source: Author

the sound artist Harry Moore to improvise on this piece. He used a bow, some glasses, and other electronic devises to create the ethereal sound that I required for this piece.

\section{Merged lights}

"Edinburgh Illuminations" was performed concurrently with a piece called "Merged Lights" (fig. 5). This composition began in Crosshaven, Co. Cork, a year earlier when I spotted the reflection of the light in the water. I tried to capture the stillness of a boat with the moving water alongside it. Based on this experience, I became fascinated with capturing lights that occurred after dark. This included observing sunsets, the cloud formations passing in front of the moon, as well as reflections on the water, and man made electronic lights. Layering of these images captured in Ireland, England, Scotland and Wales, resulted in "Merged Lights" which was performed by another sound artist Danny McCarthy. These two pieces demonstrated to the audience how "Nothing" became "Something" as it evolved through time, media and space.

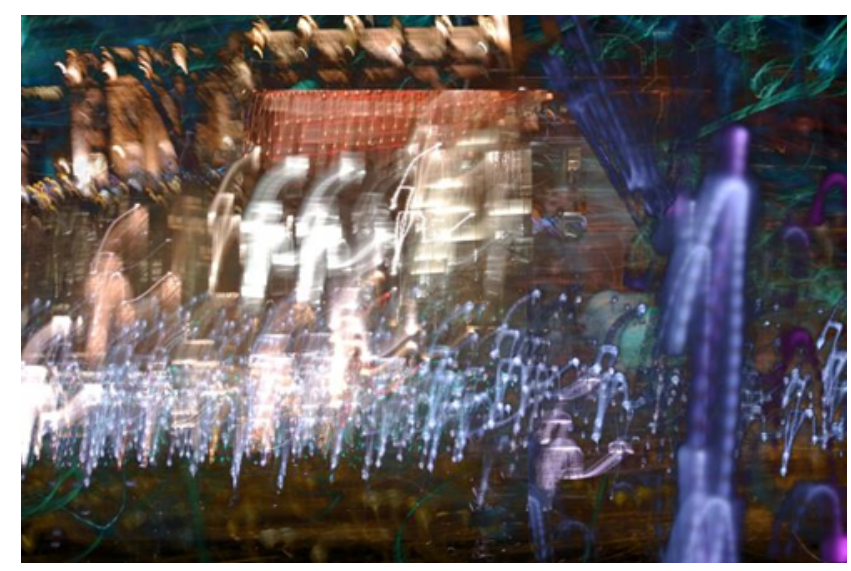

Figure 4: Edinburgh Illuminations: Merging several photographs taken as I manipulated the camera at a park of solar lights - Source: Author 


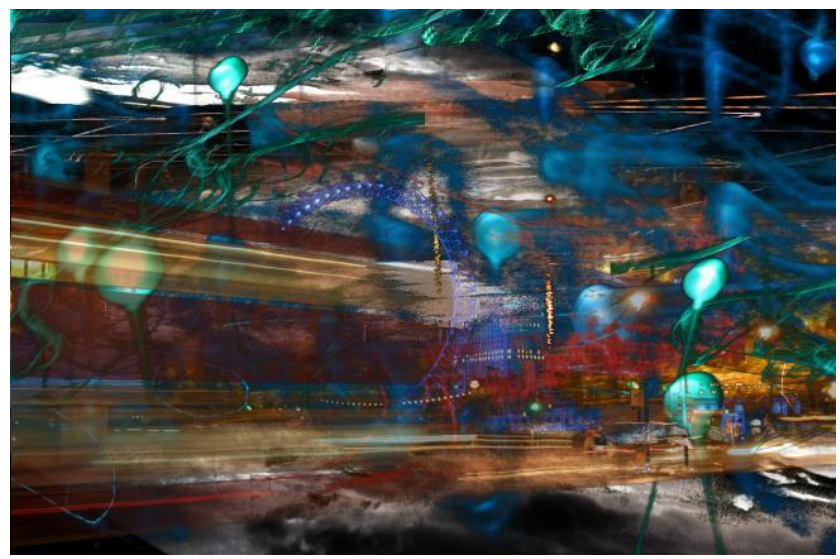

Figure 5: Merged Lights: Images from Ireland, England, Scotland and Wales unite as one - Source: Author

\section{The Great Book of Ireland}

Layering these photographs became a methodological feature of my work. In July, 2014, I decided to transfer this knowledge to the programme Adobe Audition as I began to sculpt my soundscapes as pictures. I used a series of sounds collected around Ireland for this project. I also recorded some "chance operations" using board games. I chose sounds that linked to the images that I saw when I looked at the Great Book of Ireland. I created sounds of someone making the book using wood, and even imitated John Cage's voice reading, using a computer voice sound that I found on my laptop. I spoke the names of the artists involved and sang the final section. I added an extra layer that I created by hitting a large gate under the Music Department in Sunday's Well using a contact mic to create a sense of importance to the piece. These sounds merged together as a twenty-layer piece to create my audio imagery that culminated in a performance called "Past. . . Future", in the Glucksman Gallery, as part of the "Circus on the Great Book of Ireland".

\section{Reflections reflected on Jubilate Deo}

The word "Reflections" aided a review of my earlier research and my methodological process of conveying my ideas to potential performers. It also gave me the opportunity to observe water and led to an interest in the collection of photographs of reflections.

This collection of pictures became part of an exhibition, held in the Unitarian Church, Princes Street, Cork in May 2015, but more importantly, the main picture became the trigger that inspired a new piece called "Reflections Reflected on Jubilate Deo" (fig. 6). This piece was originally written for three community choirs, one from the USA and two from Ireland. Later it was adapted for two community choirs and one organist. This piece received five public performances during the summer of 2015. One layer was based on the water, another on the trees and their reflection onto themselves and the third, the birds, flowers and bats that also appear in that picture. 


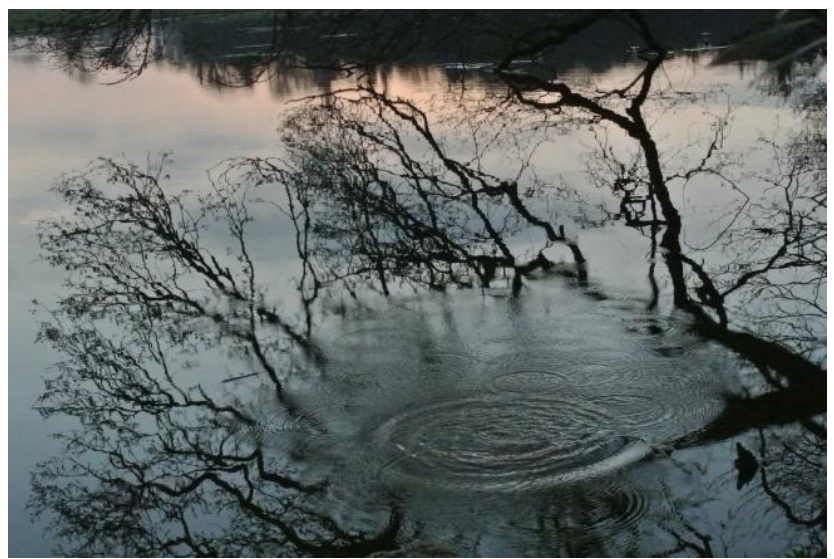

Figure 6: Reflections Reflected on Jubilate Deo — Source: Author

\section{Conclusion}

The end result is a new methodological approach that evolves from a blank canvas, the "Nothing" to "Something": a musical process, which uses photography and camera manipulation as a creative tool for composing new scores.

Special Thank You to my supervisor Mr John Godfrey and the Music Department, University College, Cork; Digital Media Department, Coláiste Stiofáin Naofa, Tramore Road, Cork; Crawford College of Art and Design and Cork College of Commerce. 